\title{
Circadian variation in physiological responses to exercise on a stationary bicycle ergometer
}

\author{
C. T. M. DAVIES and A. J. SARGEANT \\ MRC Environmental Physiology Unit, London School of Hygiene and Tropical Medicine, \\ University of London, Keppel Street (Gower Street), London WC1E 7HT
}

Davies, C. T. M. and Sargeant, A. J. (1975). British Journal of Industrial Medicine, 32, 110-114. Circadian variation in physiological responses to exercise on a stationary bicycle ergometer. The responses of six healthy male subjects to submaximal and maximal exercise on a stationary bicycle ergometer have been investigated over a 24-hour period. Measurements were made on each subject at approximately three-hourly intervals and they included minute ventilation at a carbon dioxide output of $1.51 \mathrm{~min}^{-1}\left(\dot{V}_{\mathrm{E} 1.5}\right)$, tidal volume at a fixed $\dot{V}_{E}$ of $301 \mathrm{~min}^{-1}$ $\left(\mathrm{V}_{\mathrm{T}}\right.$ 30), oxygen intake $\left(\dot{\mathrm{Vo}}_{2}\right)$ at a work load $(\mathrm{W})$ of $150 \mathrm{~W}\left(\dot{\mathrm{Vo}}_{2} 150\right)$, tympanic temperature $\left(T_{\text {ty }}\right)$ and cardiac frequency at a $\dot{V}_{2}$ of $1.51 \mathrm{~min}^{-1}\left(f_{\mathrm{H}} 1.5\right)$. The experiments were conducted in three parts: on the first occasion two subjects were measured during exercise; on the second occasion a further four subjects were observed in a similar way but starting from a baseline of zero load, and the measurements also included an estimate of cardiac output ( $\dot{Q})$ using a rebreathing technique. Finally the maximum aerobic power output ( $\dot{V}_{2}$ max) was measured in three of the subjects in early morning and late evening. Diet and habitual physical activity were held constant between the exercise test on all three occasions.

The results show that in the first two subjects $f_{H} 1.5$ and $T_{\text {ty }}$ had a rhythmic pattern of variation with time of day whereas $\dot{V}_{E} 1 \cdot 5, V_{T 30}$, and $\dot{V}_{O_{2}} 150$ remained fairly constant. The variation in $\mathrm{f}_{\mathrm{H}} 1.5$ was associated with $\mathrm{T}_{\text {ty }}$; the two variables reached a minimumat $\sim 0500 \mathrm{hr}$ and a maximum at $\sim 1200 \mathrm{hr}$. These results were confirmed on the remaining subjects but the changes in $f_{H} 1.5$ and $T_{t y}$ were shown to be more variable and reduced in magnitude. Further, if the changes were calculated from a baseline of zero load, it was shown that the absolute changes observed in $f_{H} 1.5$ and $T_{\text {ty }}$ were not due to the exercise per se but to changes in the basal level from which each subject operated. In addition it was shown that $\dot{V}_{2}$ max and $\mathbf{Q}$ remained constant and were independent of the time of day.

It is concluded that provided the exercise test conditions are rigidly standardized and subjects exercise from a controlled baseline there is no evidence for circadian variation in the change of responses to work at submaximal or maximal effort.

There is a growing volume of literature on the effects of circadian rhythms on the physiological performance of man at rest, during sleep, and while engaged in various physical activities (see Kleitman (1949) and Mills (1966) for general review) but to our knowledge no comprehensive study has been undertaken of the effects of time of day on physical work output and exercise tolerance. Many authors have noted changes of body temperature and cardiac frequency at rest (Conroy and Mills, 1970) and have presented data on athletic performance at two or more different times during the day (Conroy and O'Brien, 1973; Wahlberg and Åstrand, 1973) but no detailed study of the responses to submaximal and maximal exercise throughout a 24-hour period has been attempted.

In the present investigation six healthy male subjects have been studied during work on a stationary bicycle ergometer at three-hourly intervals throughout a day and the following night. A preliminary report on the first two subjects measured has already been given (Crockford and Davies, 1969). 
Material and methods

The six subjects were required to attend the laboratory at $0800 \mathrm{am}$ in the postabsorptive state. Their physical characteristics are given in Table 1 . The experiments were

TABLE 1

Physical Characteristics of the Six Subjects

\begin{tabular}{|c|c|c|c|c|}
\hline \multicolumn{2}{|c|}{ Subject } & $\begin{array}{l}\text { Age } \\
(y r)\end{array}$ & $\begin{array}{l}\text { Height } \\
(m)\end{array}$ & $\begin{array}{c}\text { Weight } \\
(\text { kg) }\end{array}$ \\
\hline $\begin{array}{l}\text { GWC } \\
\text { CTMD } \\
\text { SR } \\
\text { AL } \\
\text { MP } \\
\text { MB }\end{array}$ & $\begin{array}{l}. . \\
\ldots \\
\ldots \\
. . \\
\ldots\end{array}$ & $\begin{array}{l}35 \\
35 \\
21 \\
32 \\
30 \\
32\end{array}$ & $\begin{array}{l}1.74 \\
1 \cdot 78 \\
1.64 \\
1 \cdot 73 \\
1.80 \\
1 \cdot 77\end{array}$ & $\begin{array}{l}74 \cdot 5 \\
73 \cdot 9 \\
62 \cdot 0 \\
75 \cdot 4 \\
81 \cdot 0 \\
69 \cdot 0\end{array}$ \\
\hline $\begin{array}{l}\text { Mean } \\
\pm S D\end{array}$ & $\begin{array}{l}. . \\
\ldots\end{array}$ & $\begin{array}{r}30.8 \\
\pm 5.2\end{array}$ & $\begin{aligned} & 1.74 \\
\pm & 5.4\end{aligned}$ & $\begin{array}{r}72.6 \\
\pm 6.5\end{array}$ \\
\hline
\end{tabular}

conducted in three parts. On the first occasion two subjects (GWC and CTMD) were studied during submaximal exercise at regular intervals over a 27 -hour period. On the second occasion the remaining four subjects were similarly studied, and on the final occasion the maximal aerobic power of three of the subjects were measured at $0800 \mathrm{hr}$ in the morning and $1800 \mathrm{hr}$ in the evening of the same day. Throughout each experimental period attempts were made rigidly to standardize the diet and physical activity of each subject. The following routine was carried out: the subjects were measured sequentially on the bicycle ergometer. A standard progressive submaximal test was given to each subject at three-hourly intervals in which the work load was raised every 5 minutes. At least five work loads were performed, the aim being to span the whole range of the subjects' submaximal work capacity. In the first pair of subjects exercise was started at $50 \mathrm{~W}$ but in the last four subjects, who were studied on a separate occasion, a baseline of zero load was used. This enabled changes in exercise performance to be calculated (Davies and Crockford, 1971; Whipp and Wasserman, 1972). On finishing the bicycle test, the subject was allowed to eat a measured portion from a standard diet which was prepared in advance. The diet was so arranged that the food was equivalent to a 24-hour energy intake of $11220 \mathrm{~kJ}$, and each intake after exercise was equivalent to 1420 kJ. The food contained $65 \%$ carbohydrate, $20 \%$ fat, and $15 \%$ protein, and care was taken to offer the subject as much variety as possible in small portions. A fluid intake of $25 \mathrm{ml}$, which if not water was accounted for in the calorie balance, was allowed. Following the exercise the subjects were allowed to rest or read or listen to the radio and to take light exercise (walk around, play table tennis, etc). The light exercise periods were not allowed to exceed 30 minutes of the total time between each definite bicycle ergometer test. Immediately before the beginning of the exercise test the subject voided his bladder.
During exercise oxygen intake $\left(\dot{\mathrm{V}}_{2}\right)$ and pulmonary ventilation $\left(\dot{\mathrm{V}}_{\mathrm{E}}\right)$ were measured using a standard open circuit technique (Davies and Shirling, 1967), and body core temperature $\left(T_{t y}\right)$ was monitored from a thermistor placed close to the tympanic membrane. The thermistor was heavily insulated from the outside environment and was kept in situ throughout the 24 hours of the experiment. Cardiac frequency $\left(f_{H}\right)$ was measured using a differential electrocardiograph amplifier and instantaneous ratemeter, and cardiac output was estimated in four of the six subjects using a $\mathrm{CO}_{2}$ rebreathing technique (Jones et al., 1967). In the event of an unsuccessful plateau $\mathrm{PvCO}_{2}$ was estimated by extrapolation. No correction was made for the downstream phenomenon, arterialized blood $\mathrm{PCO}_{2}$ was not taken, and cardiac output (Q) was computed using a program devised by Godfrey (1970) assuming a normal dead space for each subject. Further details and discussion of the limitations of the method for measuring $Q$ are given by Godfrey and Davies (1970) and Godfrey et al. (1971).

Maximal aerobic power ( $\mathrm{VO}_{2}$ MAX) was measured using a continuous exercise test in which the subject started at approximately $90 \%$ of his maximal work level predicted from his previous submaximal responses. The criteria for maximal performance were that $\dot{\mathrm{V}}_{2}$ showed no further increase with increasing work load $(W)$ and plateau values of $\dot{V}_{2}$ agreed within $\pm 5 \%$ (Davies, 1968).

\section{Results}

The results collected on the first pair of subjects (GWC and CTMD) showed that $f_{H_{1} .5}$ and $T_{\text {ty }}$ varied with the time of day whereas $\dot{V}_{2}$ at a fixed rate of work, $\dot{V}_{E} 1.5$, and $V_{T} 30$ remained fairly constant. The variations in $f_{H_{1} .5}$ and $T_{\text {ty }}$ were associated $(r=$ $+0.47, P<0.001$ ); both variables reached a minimum at $05.00 \mathrm{hr}$ followed by a gradual rise throughout the morning to reach a maximum between 14.00 and $18.00 \mathrm{hr}$. The rise in $T_{\text {ty }}$ and in $f_{\mathrm{H}} 1.5$ was of the order $0.8^{\circ} \mathrm{C}$ and 14 beats min $^{-1}$ respectively. These results were confirmed by observations on the remaining subjects during phase 2 of the study but the change in $T_{t y}$ and $f_{H} 1.5$ was shown to be more variable and reduced in magnitude (Fig. 1). In subject $A L, T_{t y}$ rose sharply in the morning, reaching a maximum at $12.00 \mathrm{hr}$, remained fairly constant during the day, and then fell sharply in the night, whereas the $T_{t y}$ in SR, MB and MP varied more rhythmically. In these three subjects, a $T_{\text {ty }}$ minimum was reached at $05.00 \mathrm{hr}$ and a maximum between $15.00 \mathrm{hr}$ and $17.00 \mathrm{hr}$. The inter-subject variability of $f_{H} 1.5$ was less than for $T_{\text {ty }} ; f_{H ~} 1.5$ rose in the morning and fell during the night, but in contrast to the results on CTMD and GWC no well-defined maximum was observed (Fig. 1). The mean differences between day and night time $f_{H ~ 1.5}$ and $T_{t y}$ values for the six subjects were $0.76^{\circ} \mathrm{C}$ and 7 beats $\min ^{-1}$ respectively.

The results shown in Fig. 1 indicate the absolute changes of $f_{H} 1.5$ and $T_{t y}$ during exercise with time of day but from these data it is not possible to ascer- 


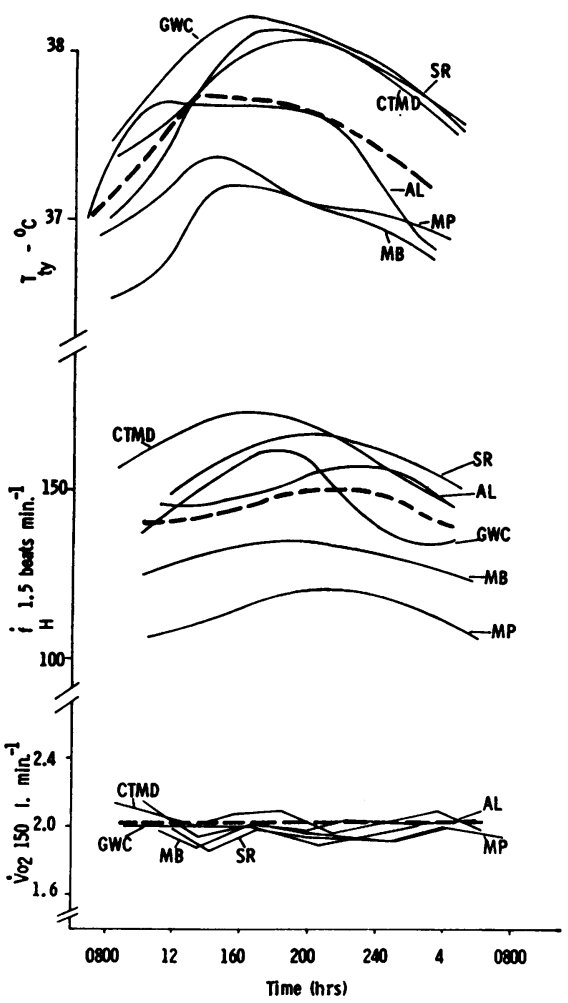

FIG. 1. Absolute changes in $\mathrm{fH}_{\mathrm{1}_{15}}, \mathrm{~T}_{\mathrm{ty}}$, and $\mathrm{VO}_{2150}$ with time of day. Individual and mean $(---)$ values for six subjects. $T_{\text {ty }}$ represents the aural temperature recorded at the end of 20 minutes' continuous submaximal test. They may not be taken as representative steady state values of $T_{t y}$ which usually require 45 minutes of exercise to establish due to the high thermal capacity of the body at the onset of work.

tain whether they reflect a genuine circadian variation in submaximal exercise performance or whether they are merely a consequence of a change in the physiological baseline from which each subject was

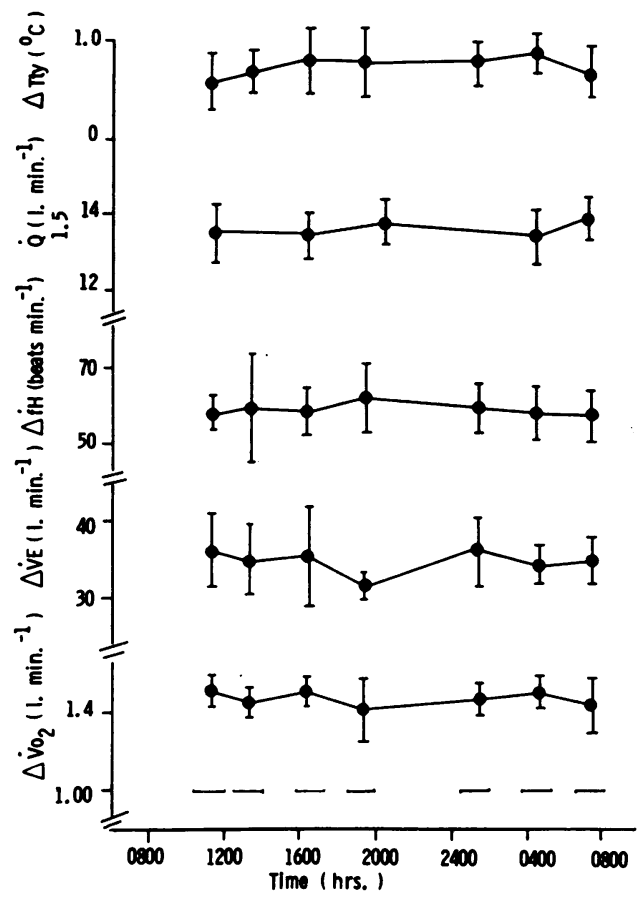

FIG. 2. Changes in exercise tympanic temperature $\left(\Delta T_{t y}\right)$, cardiac frequency at given $\dot{V} o_{2}$ of $1.51 \mathrm{~min}^{-1}$ $\left(\Delta \mathrm{f}_{\mathrm{H}}\right)$, minute ventilation at given $\dot{\mathrm{V}} \mathrm{co}_{2}$ of $1.51 \mathrm{~min}^{-1}$ $\left(\Delta \dot{\mathrm{V}}_{\mathrm{E}}\right)$, and oxygen intake at given workload of $150 \mathrm{~W}$ $\left(\Delta \dot{\mathrm{VO}}_{2}\right)$ measured from a baseline of zero load and cardiac output at given $\dot{V}_{2}$ of $1.51 \mathrm{~min}^{-1}$. Mean $\pm S D$ data for four subjects. The bars at the bottom of the figure indicate the mean $\pm S D$ of the times during which the measurements were taken.

operating. In subjects CTMD and GWC it was not possible to answer this question since the first work load performed by each subject was $50 \mathrm{~W}$ but in the second siries of experiments on four subjects the measurements were repeated from a baseline of

TABLE 2

Responses to Maximal Exercise Measured in three SubJects at 0800 HR AND 1800 HR ON THE SAME DAy

\begin{tabular}{|c|c|c|c|c|c|c|c|c|c|}
\hline & \multirow{2}{*}{\multicolumn{2}{|c|}{ Subject }} & & \multicolumn{3}{|c|}{0800 hours } & \multicolumn{3}{|c|}{1800 hours } \\
\hline & & & & $\underset{\left(l \min ^{-1}\right)}{\dot{V}_{\mathbf{m a x}}}$ & $\begin{array}{l}\dot{\mathrm{V}} \mathrm{o}_{2} \max \\
\left(\operatorname{lmin}^{-1}\right)\end{array}$ & $\underset{\text { (beats } \text { min }^{-1} \text { ) }}{\mathrm{f}_{\mathrm{max}}}$ & $\begin{array}{l}\dot{\mathrm{V}}_{\mathrm{E} \max } \\
\left(\operatorname{lmin}^{-1}\right)\end{array}$ & $\begin{array}{l}\dot{V_{o}} \max _{\max } \\
\left(l \min ^{-1}\right)\end{array}$ & $\begin{array}{c}\mathrm{f}_{\mathrm{H} \max } \\
\text { (beats } \text { min }^{-1} \text { ) }\end{array}$ \\
\hline $\begin{array}{l}M B \\
A L \\
S R\end{array}$ & $\begin{array}{l}\ldots \\
\ldots \\
\ldots\end{array}$ & $\begin{array}{l}\cdots \\
\cdots \\
.\end{array}$ & $\begin{array}{l}\cdots \\
\cdots \\
.\end{array}$ & $\begin{array}{l}166 \cdot 48 \\
145 \cdot 01 \\
130 \cdot 34\end{array}$ & $\begin{array}{l}4 \cdot 58 \\
3 \cdot 71 \\
3 \cdot 14\end{array}$ & $\begin{array}{l}174 \\
184 \\
188\end{array}$ & $\begin{array}{l}155 \cdot 39 \\
150 \cdot 62 \\
106 \cdot 78\end{array}$ & $\begin{array}{l}4 \cdot 36 \\
3 \cdot 75 \\
2 \cdot 90\end{array}$ & $\begin{array}{l}179 \\
180 \\
188\end{array}$ \\
\hline $\begin{array}{l}\text { Mean } \\
\text { SD }\end{array}$ & $\begin{array}{l}\cdots \\
\ldots\end{array}$ & $\begin{array}{l}\ldots \\
\ldots\end{array}$ & $\begin{array}{l}\cdots \\
\cdots\end{array}$ & $\begin{array}{r}144 \cdot 27 \\
\pm 18 \cdot 18\end{array}$ & $\begin{array}{r}3.81 \\
\pm 0.73\end{array}$ & $\begin{array}{r}182 \\
\pm 7\end{array}$ & $\begin{array}{r}137.60 \\
\pm 26.79\end{array}$ & $\begin{array}{r}3.67 \\
\pm 0.73\end{array}$ & $\begin{array}{r}182 \\
\pm 5\end{array}$ \\
\hline
\end{tabular}


pedalling against zero load. In addition, cardiac output, and at a later stage in three of the subjects, maximal aerobic power were measured. The data for submaximal exercise are shown in Figure 2. It will be seen that $\Delta \dot{V}_{2}$ for given $\dot{W}$ and $\dot{V}_{E}$ remain unchanged throughout the period of the study. Calculating the results from a baseline of zero load also obliterates the variation in $T_{\text {ty }}$ previously observed and markedly reduces the rise in $\mathrm{f}_{\mathrm{H}}$. Cardiac output for a given $\mathrm{V}_{2}$ remains constant during the 24 hours of the experiment.

\section{Maximal performance}

The responses to maximal exercise measured in the early morning and late evening are shown in Table 2.

The mean maximal cardiac frequencies were identical during the two periods of the day; $\dot{V}_{2} \max$ and $\dot{V}_{\mathbf{E} \max }$ were $0.141 \mathrm{~min}^{-1}$ and $6.71 \mathrm{~min}^{-1}$ lower during the evening but none of these differences was statistically significant.

\section{Discussion}

The initial experiments on two healthy male subjects (CTMD and GWC) were designed to evaluate the responses to submaximal exercise in relation to time of day, with diet and habitual activity held constant. They were repeated on a further four subjects during phase 2 of the investigation. The results show that both the circulatory and thermal responses to work vary with time of day during a 27 -hour period but the periodicity and magnitude of the changes vary for each subject (Fig. 1). This gave rise to a large intersubject variability for both $\mathrm{f}_{\mathrm{H1} \cdot 5}$ and $\mathrm{T}_{\mathrm{ty}}$. The average cardiac frequency and tympanic temperature were 7 beats $\min ^{-1}$ and $0.76^{\circ} \mathrm{C}$ higher in the day than the night. These changes were observed against a background of metabolic constancy (Fig. 1): $\dot{\mathrm{V}}_{2} 150, \dot{\mathrm{V}}_{\mathrm{E} 1.5}$, and $\dot{\mathrm{V}}_{\mathrm{T} 30}$ remained constant throughout the investigations and were independent of the time of day. These results agree closely with the observations of Klein, Wegman, and Brüner (1968) and the recent report of Wahlberg and Åstrand (1973). The latter authors found an unchanging aerobic cost of work but a significant $(\mathrm{P}<0.05)$ increase in $\mathrm{f}_{\mathrm{H}}$ of 4 beats $\mathrm{min}^{-1}$ at $100 \mathrm{~W}$ (approximately equivalent to a $\dot{\mathrm{V}}_{2}$ of $1.51 \mathrm{~min}^{-1}$ ) during the day $(15.00 \mathrm{hr})$ compared with the night $(03.00 \mathrm{hr})$ time. However, these changes are small and in our experiments no account was taken of the possible confounding influence of change in basal level from which each subject was operating during exercise. In addition, though the changes in $\mathrm{f}_{\mathrm{H}}$ at a given $\dot{\mathrm{V}}_{2}$ gave rise to a change in predicted maximal aerobic power $\left(\dot{\mathrm{V}}_{2}\right.$ max $)$, no direct measurements of this latter parameter were made in our investigation, and it is unclear whether the changes in $f_{H}$ would be reflected in comparable changes of $\mathbf{Q}$. Therefore in the second series of experiments, we repeated the exercise studies from a baseline of constant pedalling against zero load and included measurements of $\dot{Q}$ using a rebreathing technique. In the final experiments we made direct measurements of $\dot{\mathrm{VO}}_{2} \max$ in three of these four subjects in the early morning and late evening. The data from these experiments show that $\dot{Q}$ at a given $\dot{V}_{2}$, and $\dot{V}_{2}$ max remained constant (cf Wahlberg and Åstrand, 1973) and are independent of the time of day (Fig. 2; Table 2). Further, calculating the $f_{H}$ and $T_{t y}$ data from a baseline of zero load obliterates variations in circulatory and thermal responses previously observed (Fig. 1).

These results taken together are important and, contrary to our previous expectation (Crockford and Davies, 1969), suggest that provided conditions are standardized, measurements taken from fixed baseline exercise performance remain the same throughout a given 24-hour period. The observed changes in absolute $f_{H}$ and $T_{t y}$ must be due to some underlying basal circadian rhythm and not to the response to exercise per se. What therefore is the nature of this underlying rhythm which affected our earlier results? The answer may lie in our observations of $\dot{V} \mathrm{O}_{2}{ }_{150}, \dot{Q}$, and $\dot{V}_{2} \max$ in the first two and third stages of our study respectively. It will be noted that these three variables remain constant irrespective of whether they are calculated in absolute or relative $(\Delta)$ terms. This is in contrast to what has been found for subjects who have been allowed to sleep during the night (Conroy and Mills, 1970). Under these conditions $\dot{\mathrm{V}}_{2}$ shows a marked fall during the somnambulant periods. The constancy of $\dot{Q}$ and the absolute changes in $f_{H}$ imply mathematically (but not necessarily biologically) a small rhythmic change in basal cardiac stroke volume with time of day, which in turn (again by implication from our first series of experiments) must be associated with changes in $T_{t y}$. Provided posture and the effective muscle mass performing the work remain fairly constant, as in the present experiments which involved upright two-leg work on a bicycle ergometer, there is some common agreement (Bevegård and Shepherd, 1967) that a change in stroke volume usually implies a displacement of blood to the periphery, possibly to subserve the requirements of thermoregulation. Indeed, Kaneko, Zechman, and Smith (1968) have shown that rhythmic changes in peripheral blood flow do occur. They observed that arm blood flow measured by venous occlusion plethysmography reaches a maximum in the later afternoon or early evening which corresponds with our circulatory observations. Thus one is led to the conclusion that the changes in $f_{H}$ we originally observed must be thermogenic and not metabolic in origin.

A change in $T_{t y}$ can only result from an increase in the dissipation or conservation of body heat. Several 
authors (Mills, 1966) have noted a rhythmic change in skin temperature (Ts), the curve relating to time of day being the mirror image of that found to $T_{t y}$. In a previous study (Crockford, Davies, and Weiner, 1970) we also noted a rise in Ts during the night but a maximum in the $T_{\text {ty }}$ at sweat onset during the day. Taken together all these data and those of the present investigation suggest that variations in heat loss mechanisms, particularly the interaction between skin, blood flow, and sweat onset, may be more important than heat production in regulating the rhythmic basal changes in observed $f_{H}$ and $T_{\text {ty }}$. In exercise these factors will be operative, but our data merely indicate that they will give rise to changes of absolute $f_{H}$ and $T_{t y}$ of the same order as those seen during baseline exercise during which no external work is performed. Thus in practical terms, particularly with reference to circadian variation of performance, they will have little bearing. Aerobic power output and physiological response to a given change in work output during exercise on a stationary bicycle ergometer remain constant and independent of the time of day.

We wish to thank Mr. G. W. Crockford for his active participation in the early experiments and Mr. Stephen Riggs for technical assistance. We are deeply indebted to the four subjects who took part in the second series of experiments for their wholehearted co-operation and cheerfulness in the face of stringent demands.

\section{References}

Bevegård, B. S. and Shepherd, J. T. (1967). Regulation of the circulation during exercise in man. Physiological Reviews, 47, 178-213.

Conroy, R. T. W. L. and Mills, J. N. (1970). Human Circadian Rhythms. J. and A. Churchill, London.

- and O'Brien, M. (1973). Diurnal variation in athletic performance. Journal of Physiology, 236, 51P.

Crockford, G. W. and Davies, C. T. M. (1969). Circadian variation in responses to submaximal exercise on a bicycle ergometer. Journal of Physiology, 201, 94-95P.

$\longrightarrow,-$, and Weiner, J. S. (1970). Circadian changes in sweating threshold. Journal of Physiology, 207, 26-27P.

Davies, C. T. M. (1968). Limitations to the prediction of maximum oxygen intake from cardiac frequency measurements. Journal of Applied Physiology, 24, 700-706.

- and Crockford, G. W. (1971). The kinetics of recovery oxygen intake and blood lactic acid concentration measured to a baseline of mild steady work. Ergonomics, 14, 721-731.

- and Shirling, D. S. (1967). The rapid sampling storage and analysis of expired air. Ergonomics, 10, 349359.

Godfrey, S. (1970). Manipulation of the indirect Fick principle by digital computer program for the calculation of exercise. Respiration, 27, 513-532.

- and Davies, C. T. M. (1970). Estimates of arterial $\mathrm{PCO}_{2}$ and their effect on the calculated values of cardiac output and dead space on exercise. Clinical Science, 39, 529-537.

$\longrightarrow,-$, Wozniak, E., and Barnes, Carolyn, A. (1971). Cardio-respiratory response to exercise in normal children. Clinical Science, 40, 419-431.

Jones, N. L., Campbell, E. J. M., McHardy, G. J. R., Higgs, B. E., and Clode, M. (1967). The estimation of carbon dioxide pressure of mixed venous blood during exercise. Clinical Science, 32, 311-327.

Kaneko, M., Zechman, F. W., and Smith, R. E. (1968). Circadian variation in human peripheral blood flow levels and exercise responses. Journal of Applied Physiology, 25, 109-114.

Klein, K. E., Wegman, H. M., and Brüner, H. (1968). Circadian rhythm in indices of human performance, physical fitness and stress resistance. Aerospace Medicine, 39, 512-518.

Kleitman, M. (1949). Biological rhythms and cycles. Physiological Reviews, 29, 1-30.

Mills, J. N. (1966). Human circadian rhythms. Physiological Reviews, 46, 128-171.

Wahlberg, I. and Åstrand, I. (1973). Physical work capacity during the day and at night. Work-Environment-Health, 10, 65-68.

Whipp, B. J. and Wasserman, K. (1972). Oxygen uptake kinetics for various intensities of constant-load work. Journal of Applied Physiology, 33, 351-356.

Received for publication 15 August 1974.

Accepted for publication 28 November 1974. 